\title{
Asociaciones, educación y maestro en el Bolívar Grande (Colombia), 1870-1899*
}

\section{Resumen}

El presente artículo tiene como objetivo central analizar las principales características de las asociaciones creadas en el tránsito del Liberalismo radical a la Regeneración en el Bolívar Grande entre 1870-1899. Inscrito dentro de la tendencia historiográfica en América Latina, que pretende examinar el tema de la formación del Estado-nación desde múltiples variables, que tiene en las sociabilidades y la educación pública, dos espejos muy relevantes como análisis de interpretación, estas líneas muestran que el mundo asociativo creado durante este periodo no solo fue un factor que coadyuvó a la popularización de la educación y difusoras de un mismo lenguaje instruccionista, sino que también se constituyen en un elemento de continuidad entre estos dos proyectos políticos. Concluyo que dichas civilidades, significaron un puente para forjar en la labor del maestro, una profesión modelo de la sociedad y una herramienta que, unida a la educación, se convirtieron en vehículo esencial para hacer Estado y edificar sociedad en el Bolívar Grande.

\section{Palabras clave}

Tesauro: asociaciones, educación, maestro, ciudadanía.

Autor: Estado-nación.

Referencia para citar este artículo: Salas Martínez, Luisinho Eder. "Asociaciones, educación y maestro en el Bolívar Grande (Colombia), 1870-1899". Anuario de Historia Regional y de las Fronteras 23.2 (2018): 257-284. DOI: 10.18273/revanu.v23n2-2018009

Fecha de recepción: 17/06/2018

Fecha de aceptación: 22/06/2018

Luisinho Eder Salas Martínez: estudiante de tercer semestre del Doctorado en Historia con la Universidad Autónoma de Zacatecas "Francisco García Salinas", México. Magíster en Historia por la Universidad Autónoma de Zacatecas "Francisco García Salinas", México (2016). Historiador, egresado de la Universidad de Cartagena (2009). Sus líneas de Investigación son: Historia política e historia social de la educación, en Colombia y su Región Caribe en las tres últimas décadas del siglo XIX e inicios del XX. Código ORCID: https://orcid.org/0000-0001-6890-1305. Correo electrónico: luisinhoeder@hotmail.com.

\footnotetext{
* Este artículo sintetiza algunas de los hallazgos de mi tesis de maestría. "Educación, maestro y ciudadanía. De la transición del Liberalismo radical a la Regeneración: el caso del Bolívar Grande, 1870-1899”, desarrollada en la Universidad Autónoma de Zacatecas Francisco García Salinas. La investigación contó con el apoyo de una beca del Conacyt, Argentina.
} 


\title{
Associations, Education and the Teacher in the Bolivvar Grande (Colombia), 1870-1899
}

\begin{abstract}
The main objective of this article is to analyze the main characteristics of the associations created in the transition from radical Liberalism to Regeneration in the Bolivar Grande between 1870-1899. These, inscribed within the historiographic trend in Latin America, which seeks to examine the issue of the formation of the nation-state from multiple variables, which has in sociabilities and public education, two very relevant mirrors as interpretative analysis, these lines show that the associative world created during this period was not only a factor that contributed to the popularization of education and diffusers of the same instructional language, but also constitutes an element of continuity between these two political projects. I conclude that these civilities, meant a bridge to forge a teacher's job, a model profession of society and a tool that, together with education, became an essential vehicle to make state and build society at the Bolivar Grande.
\end{abstract}

Keywords

Thesaurus: Associations, Education, Teacher, Citizenship. Author's keywords: Nation-State.

\section{Associações, educação e o professor na Bolívar Grande (Colômbia), 1870-1899}

\section{Resumo}

O principal objetivo deste artigo é analisar as principais características das associações criadas na transição do liberalismo radical para a regeneração no Bolívar Grande entre 1870-1899. Inscrito dentro da tendência historiográfica na América Latina, que procura examinar a questão da formação do Estado-nação a partir de múltiplas variáveis, que tem nas sociabilidades e educação pública, dois espelhos muito relevantes como análise interpretativa, estas linhas mostram que o mundo associativo criado durante este período não foi apenas um fator que contribuiu para a popularização da educação e difusores da mesma língua instrucional, mas também constitui um elemento de continuidade entre esses dois projetos políticos. Concluo que essas civilidades significaram uma ponte para forjar o trabalho do professor, uma profissão modelo da sociedade e uma ferramenta que, junto com a educação, se tornou um veículo essencial para desenvolver o estado e construir sociedade no Bolivar Grande.

Palavras-chave

Thesaurus: associações, educação, professor, cidadania.

Palavras-chave do autor: Estado-nação. 


\section{Presentación}

En los últimos años un número significativo de intelectuales del Clío en distintos espacios geográficos de América Latina y de Europa, se han dado a la tarea de estudiar las diferentes visiones y el papel que cumplieron las asociaciones formales e informales en el marco de la legitimación de discursos hegemónicos, el proceso de vinculación obligatorio a lo que crea e impone el Estado, en el tránsito de interacciones tradicionales a modernas, el lugar que ocupan a pensar la nación y a los distintos grupos sociales. Así mismo, los que analizan este concepto como herramientas en el terreno de la política moderna y la construcción de nuevas redes de poderes de tipo civil que se construyen fuera del control del Estado y no menos importante, la función que efectúan en el proceso de construcción del Estado-nación, como una forma de pedagogía cívica, mediante la cual el ciudadano hace el aprendizaje de la cosa pública, pero sobre todo en el acompañamiento en la invención del individuo como sujeto principal, la valorización de los lazos contractuales, el ideal de igualdad, el imperio de la opinión y la soberanía de la colectividad. ${ }^{1}$

En el caso específico de Colombia y su región Caribe, los pocos estudios existentes han profundizado en el papel que cumple el fenómeno asociativo y las elites en el proyecto de formación nacional y su estrecha relación con la política moderna y la Iglesia católica, la importancia de la correlación en la triada asociaciones-prensa-elecciones, como eje central de muchos de los procesos políticos del siglo XIX colombiano,

\footnotetext{
${ }^{1}$ Agulhon Maurice, "Clase obrera y sociabilidad antes de 1848”, Historia Vagabunda (México: Instituto Mora, 1994) 55-85; "Los chambrée en la baja Provenza: historia y etnología", Historia Vagabunda (México: Instituto Mora, 1994) 18-55; E. P. Thompson, "Tiempo, disciplina de trabajo y capitalismo industrial”, Costumbres en Común (Barcelona: Ed. Crítica, 2000) 394-452; Eric Wolf, "Relaciones de parentesco, de amistad y de patronazgo en las sociedades complejas", Teoría Social e Historia, Comp. Joan Vendrell Ferre (Madrid: Alianza Editorial, 1980) 249-273. François Guerra, "Una modernidad alternativa", modernidad e independencias, ensayos sobre las revoluciones hispánicas, coord. François Guerra (México: Fondo de Cultura Económica, 1993) 86-113; Rene Amaro Peñaflores y Judith Rivas Hernández, De los procesos de consolidación y ruptura de las mutualistas a los primeros sindicatos en Zacatecas, 1870-1926 (Zacatecas: Zezen Baltza Editores, Universidad Autónoma de Zacatecas, 2015) 385; Rubio Hernández y otros, "Movimiento asociativo en Santiago de Cuba: un acercamiento a sus orígenes y evolución durante el siglo XIX”, Historia Caribe 11.26 (2016): 51-75; Pilar González Bernaldo de Quirós, "La sociabilidad y la historia política", Electrónica: Nuevo Mundo Mundos Nuevos (2008); "Pedagogía societaria y aprendizaje de la nación en el Río de la Plata", Inventando la nación: Iberoamérica siglo XIX, coords. Antonio Annino y François-Xavier Guerra (México: Fondo de Cultura Económica, 2003); "Sociabilidad y regímenes de lo social en sociedades post-imperiales: Una aproximación histórica a partir del caso argentino durante el largo siglo XIX", Sociabilidades en la historia, coords. Santiago Castillo y Montserrat Duch (Madrid: La Catarata-Asociación de Historia Social, 2015) 213-234; Paula Bruno, Sociabilidades y vida cultural, Buenos Aires, 1860-1930 (Bernal: Universidad Nacional de Quilmes, 2014) 320; Sonia Pérez Toledo, Trabajadores, espacio urbano y sociabilidad en la Ciudad de México, 1790-1867 (México: Miguel Ángel Porrúa, Universidad Autónoma Metropolitana, 2011); Eugenia Molina, "Sociabilidad y redes políticointelectuales: Algunos casos entre 1800 y 1852", Cuadernos del CILHA 12.14 Argentina, Universidad Nacional de Cuyo (2011): 19-54; Betria Mercedes, "Para una nueva lectura sobre la Generación del 37: mazzinismo y sociabilidades compartidas en la construcción de la identidad nacional argentina", Construcciones identitarias en el Río de la Plata, siglos XVIII-XIX, coords. Arrigo Amadori y Mariano di Páscuale (Rosario: Prohistoria, 2013): 135-162; Paula Caldo y Sandra Fernández, "Sobre el sentido de lo social: asociacionismo y sociabilidad. Un breve balance", Ciudad oblicua. Aproximaciones a temas e intérpretes de las entreguerras rosarina, comps. Sandra Fernández y Óscar Videla (Rosario: La Quinta Pata \& Camino Ediciones, 2018) 145-151.
} 
en el lugar que ocupa para el diseño de los valores e ideales, las representaciones e imaginarios, las prácticas y conductas existentes con miras a instalar un nuevo modelo relacional, considerado necesario para darle vida a la república que van perfilando las diferentes lealtades e identidades políticas del siglo XIX; y las distintas formas y lugares en que se construyen estas interacciones en el seno de la política regional. ${ }^{2}$

Pese a estos avances, existen interrogantes y vacíos aún sin responder sobre este tema central en el complejo mundo asociativo y educativo de Colombia en las tres últimas décadas del siglo XIX, lo que es mucho más notable en la región del Caribe colombiano, particularmente en el Bolívar Grande. ${ }^{3}$ Sobre este territorio interrogantes como: ¿qué papel cumplieron las sociabilidades entre 1870-1899 para la puesta en marcha de un mismo lenguaje instruccionista y en uno de los impulsos al fomento de la educación pública en el Bolívar Grande, tanto para el Liberalismo radical como para la Regeneración?, ¿qué relación existió entre sociabilidades, educación, maestro

\begin{abstract}
${ }^{2}$ Gilberto Loaiza Cano, Sociabilidad, religión y política en la definición de la nación (Colombia, 1820-1886), (Bogotá: Universidad Externado de Colombia, 2011) 470; “Temporalidad, Sociabilidad y Democracia. Colombia y su Siglo XIX”, Historia Caribe 11.26 (2016): 177-210; "La masonería y las facciones del liberalismo colombiano durante el siglo XIX. El caso de la masonería de la Costa Atlántica", Historia y Sociedad 13 (2007): 65-89. "Hombres de sociedades (Masonería y sociabilidad político-intelectual en Colombia e Hispanoamérica durante la segunda mitad del siglo XIX)", Historia y Espacio (2001): 93131; Andrés Álzate García, "Asociaciones, prensa y elecciones. Sociabilidades modernas y participación política en el régimen radical colombiano 1863-1876" (Tesis, Maestría en Historia, Universidad Nacional de Colombia, Medellín, 2010) 236; Luis Alarcón Meneses, "Sociabilidad y relaciones de poder en el Caribe colombiano durante el régimen federal", Historia Caribe.2 (1996): 35-42. Francisco Ortega, "Sociabilidad, asociacionismo y civilidad en la primera $\mathrm{mitad} / \mathrm{del} / \mathrm{siglo} / \mathrm{XIX} /$ neo-granadino. /Una /aproximación / conceptual"https://www.academia.edu/15111086/Sociabilidad_asociacionismo_y_civilidad_en_la_ primera_mitad_del_siglo XIX_neogranadino._Una_aproximaci\% $\bar{C} 3 \%$ B $3 n \_c o n c e p t u a \bar{l}$ (2014); Gloria Arango de Restrepo, Sociabilidades católicas, entre la tradición y la modernidad. Antioquia, 18701930 (Medellín: Universidad Nacional de Colombia, Sede Medellín-La Carreta Editores, 2004) 147. "Las cofradías, las asociaciones católicas y sus formas/de/sociabilidad, Antioquia, siglo XIX", Revista de Extensión Cultural 34-35 (1995): 94-104; Juliana Álvarez Olivares, "Hacerse artesano: identidad, diversidad y sociedad: Medellín, 1854-1880" (Tesis, Maestría en Historia, Universidad Nacional de Colombia-Sede Medellín, 2008); Américo Carnicelli, Historia de la masonería colombiana, 1833-1940 (Bogotá: Artes gráficas, 1975); Mario Arango Jaramillo, Masonería y Partido Liberal Otra cara en la historia de Colombia (Medellín: Corselva Editorial, 2006).
\end{abstract}

${ }^{3}$ El 15 de junio de 1857 se aprueba una ley por el congreso de la república que creó el Estado Soberano de Bolívar, al igual que los de Cauca, Cundinamarca, Boyacá y Magdalena. Su territorio comprendía los actuales departamentos de Bolívar, Atlántico, Córdoba, Sucre y el de San Andrés Islas y Providencia, con una extensión de algo más de 65. 300 kilómetros cuadrados. Solo podemos imaginar las vastas proporciones de este espacio sí tenemos presente que era más grande que el 50\% de los países europeos (Dinamarca, Bélgica, Holanda, Suiza, Eslovaquia, Bosnia-Herzegovina, Lituania, Estonia, Letonia, Eslovaquia, Moldavia, Croacia, Macedonia, Albania, entre otros), y en América era mayor en tamaño que las repúblicas de El Salvador, Belice y Costa Rica, al igual que superior a todos los países del Caribe insular, excepto Cuba. El nombre era un reconocimiento a la memoria del libertador. Durante la colonia y hasta finales del decenio de 1850 se le conoció como la provincia de Cartagena, y bajo el régimen federal se llamó Estado Soberano de Bolívar y a partir de 1886, Departamento de Bolívar. Entre 1905, 1954 y 1966 quedó reducido al actual departamento de ese nombre, pues sufrió el desprendimiento de las tres primeras unidades político-administrativas mencionadas. Véase: Sergio Paolo Solano y otros. "Ordenamiento territorial y conflictos jurisdiccionales en el Bolívar Grande (Colombia), 1800-1886", Historia Caribe.13 (2008): 65-121. Además, véase: Flórez Bolívar Roicer, "El uso privado de la autoridad pública en el Estado Soberano de Bolívar, 1863-1878" (Tesis de Maestría, Universidad Pedagógica y Tecnológica de Colombia en convenio con la Universidad de Cartagena, 2007) 300. 
y formación del Estado-nación?, ¿cuáles fueron las representaciones creadas en estas interacciones sociales de tipo laboral con respecto a la popularización de la enseñanza pública, alineación de ciudadanos y concebir al maestro de escuela como paradigma de la ciudadanía en este contexto de corte republicano? tales preguntas permanecen sin respuesta. Ahora bien, por la importancia del tema en las presentes líneas, se hará un análisis sobre las principales características de las asociaciones creadas en el transito del Liberalismo radical a la Regeneración en el Bolívar Grande entre 1870-1899 y el papel que cumplen estas interacciones institucionales en el impulso a la instrucción pública, pero además, en la formación de los nuevos ciudadanos que requería la república y en la representación del maestro como modelo de esa ciudadanía en esta parte del Caribe colombiano. La idea central que guía este artículo, es que son estas interacciones no solo un factor que coadyuvará a la popularización de la educación, difusoras de un mismo discurso instruccionista, sino además y esto va en contravía de cierta historiografía local, regional y nacional, que estudia la transición de los gobiernos liberales y regeneradores en función solo de rupturas y marcadas diferencias entre esos modelos políticos en las tres últimas décadas del siglo XIX, hasta el punto de plantear que el ascenso de la Regeneración había entrañado el desmantelamiento del sistema educativo nacional iniciado por los liberales, con respecto al fomento de la instrucción pública, y, por supuesto, en la representación que hacen del maestro como modelo de ciudadano a través de las asociaciones, sostenemos que existió una continuidad en estos proyectos políticos aparentemente disimiles de concebir el Estado. En otras palabras, serán asociaciones, si bien institucionalizadas y de distintos regímenes públicos, significaron un puente para forjar en la labor del maestro, una profesión modelo de la sociedad y una herramienta que, unida a la educación, se convirtieron en vehículo esencial para hacer Estado y edificar sociedad en este espacio geográfico.

\section{2. "Eduquemos, eduquemos"}

El 8 de mayo de 1863 representantes de los gobiernos de Antioquia, Bolívar, Boyacá, Cauca, Cundinamarca, Magdalena, Santander, Tolima y Panamá, firmaron la Constitución de Rionegro, que daría paso a la conformación de los Estados Unidos de Colombia. Esta carta constitucional es considerada la más anticlerical en la historia de Colombia. Invocaba el nombre y la autoridad del pueblo en vez del nombre de Dios. De igual forma, dinamizó la absoluta separación entre la Iglesia y el Estado. Esta Constitución recopiló en forma coherente la ideología liberal, consagró las libertades individuales, el derecho a la igualdad, la libertad de dar o recibir instrucción, la libertad de profesar cualquier religión con tal de que no fuera incompatible con la soberanía nacional o perturbara la paz, entre otros elementos. Bajo este emblema constitucional, los liberales radicales iniciaron una serie de reformas económicas, políticas y sociales. La reforma en el campo económico tuvo que ver con la instauración del libre comercio como doctrina económica que vincularía al país al mercado mundial. En el campo político, se estableció un orden federal que permitió total autonomía a los Estados de la Unión y en lo social, los radicales propusieron una clara división de poderes entre la Iglesia

${ }^{4}$ Biblioteca Nacional de Colombia (en adelante BNC) "Editorial”, La Verdad, (Cartagena) 25 de diciembre de 1877. 
y el Estado. Se trataba de transformar un país "casi colonial, conservador, intolerante y católico en una Nación republicana, secular, tolerante, ilustrada y moderna". 5 Para estos políticos había llegado la hora de encausar al territorio colombiano por las sendas del progreso y civilización, que se debía traducir precisamente en fomentar la instrucción pública para todos y todas de manera gratuita, modernizar el Estado en términos económicos, políticos, sociales, culturales y obviamente a la ampliación de la ciudadanía. La educación se constituyó en una pieza fundamental en esos propósitos de modernización para los gobiernos radicales. Hasta el punto de convertirse en una preocupación constante de su proyecto político.

Los dirigentes liberales estaban convencidos de la necesidad por educar a las clases populares y convertirlos en sujetos que reivindicarán y defendieran no solo su proyecto político, sino, además, crear las bases del anhelado progreso y la soñada civilización tan de boga en el pensamiento latinoamericano y europeo decimonónico. Por eso sus esfuerzos en crear un sistema de educación pública y por llevar la escuela de las primeras letras a todos los rincones de la república. La educación, según esta elite, era el único camino para cultivar los valores de aquel que refundaría la nación: el ciudadano y además un elemento que pretendía fortalecer la idea de cohesión nacional. ${ }^{6}$ Pero además, y aquí sigo los planteamientos que para el caso de Chile durante el siglo XIX, plantea la historiadora Sol Serrano, se buscaba con esta política de escolarización: "romper los lazos comunitarios de tipo tradicional y forjar unos nuevos basados en la racionalidad de la cultura escrita; construir una sociedad de individuos que se comportasen racionalmente en el espacio privado identificado con la familia y el trabajo y en el espacio público, identificado con la ciudadanía y la manutención del orden social". ${ }^{7}$ En otras palabras, se intentaba dejar atrás prácticas inherentes a la tradición, el rezago social y cultural que adornaba la sociedad colombiana y bolivarense, pero sobre todo impregnar a los nuevos ciudadanos de herramientas modernas como saber leer y escribir para su desenvolvimiento en la nueva sociedad de tipo republicana que se intentaba construir. En la misma prensa

\footnotetext{
${ }^{5}$ Luis Ortiz Meza, "Los radicales y la guerra civil de 1876-1877”, El radicalismo colombiano del siglo XIX, ed. Rubén Sierra Mejía (Bogotá, Universidad Nacional de Colombia, 2006) 221.

${ }^{6}$ Concebir la educación como un elemento de cohesión nacional, durante este periodo no es un acto exclusivo de Colombia. En Chile, México y Argentina también ocurre lo mismo. Véase al respecto: Sol Serrano, "La ciudadanía examinada: el control estatal de la educación en Chile, 1810-1870", Inventando la Nación. Ibero América Siglo XIX, coord. Antonio Annino y François Guerra (México: 1ra Edición, Fondo de Cultura Económica, 2003) 551-564; Milada Bazant, "La disyuntiva entre la escuela y la cosecha: entre las multas y los arrestos", El Estado de México de 1874 a 1910, coord. Pilar Gonzalbo (México, El Colegio de México, 1990) 173-189. Historia de la educación durante el Porfiriato (México: El Colegio de México, 1993). Josefina Granja, "Contar y clasificar a la infancia. Las categorías de la escolarización en las escuelas primarias de la Ciudad de México 1870-1930”, Revista Mexicana de Investigación Histórica 1.40 (2009): 217-254; Lucía Lionetti, "La función republicana de la escuela pública. La formación del ciudadano en Argentina a fines del siglo XIX”, Revista Mexicana de Investigación Educativa 10 (2005): 1225-1255.

${ }^{7}$ Sol Serrano, "La escuela chilena y la definición de lo público", Los espacios públicos en Iberoamérica, ambigüedades y problemas, Siglos XVIII y XIX, coords. François Xavier Guerra y Annick Lémpèriere (México: Centro Francés de estudios mexicanos y centroamericanos, Fondo de Cultura Económica de México, 1998) 341.
} 
regional de la época se reproducía ese interés de instruir a la población y educar para el progreso de la república. En uno de esos medios periodísticos se recalcaba:

la instrucción de las masas, debe ser hoi el tema principal de la escuela radical. Mui poco valen los derechos ciudadanos si este no sabe hacer uso de ellos; i es menester que nos repitamos cada día, a cada momento, para no olvidarlo: sin ilustración de las masas o si se quiere sin que la mayoría de los ciudadanos sepan leer i escribir al menos, el sufragio universal es una ficción, la república una mentira [...] el gobierno i el partido que lo apoya, que lo inspira deben contraerse con afán, sin descanso, a fomentar la instrucción pública, llevándola hasta la última aldea, la consecuencia de semejante trabajo será la instrucción del pueblo. ${ }^{8}$

Existió la imperiosa necesidad por educar a las masas para dotarla de sus derechos políticos. La oportunidad era histórica y el ambiente de progreso que se manejaba durante la centuria decimonónica, no solo en Colombia sino en el resto de países de América Latina era el punto del alzhéimer donde se debía llegar. Evidentemente será la educación pública uno de los puentes para lograr ese fin. En ese sentido, asumió tal elite política liberal a la instrucción pública, como el vehículo que coadyuvará al proceso de formación del Estado-nación y que permitirá la ampliación de la ciudadanía. Alfabetizando el mayor número de personas, se transitaba según una historiadora autorizada, de una "soberanía popular" a una "soberanía racional", es decir "a un sufragio capacitario, que tenía como fin hacer coincidir al pueblo teórico de la soberanía con el pueblo real de la política".

Así las cosas, una de las iniciativas emprendidas bajo el gobierno de Eustorgio Salgar (1870-1872), con el apoyo del entonces secretario del interior Felipe Zapata, fue la puesta en marcha del Decreto Orgánico de Instrucción Pública Primaria en 1870 (DOIP). Decreto que como su nombre lo indica hace referencia a la promulgación de principios, desde la misma raíz del elemento educativo, es decir, fue una disposición integral de todos los asuntos inherentes a la instrucción pública. Constaba de 10 capítulos y 294 artículos, en los que se establecía la instrucción pública y gratuita, dentro de un sistema uniforme dirigido y supervisado por el gobierno federal. Además, se describía la naturaleza de la enseñanza y la preparación de maestros. Establecía una dirección general primaria, como la oficina central de administración. Dividió la instrucción pública en tres grandes ramos: la enseñanza, la inspección y la administración. Creó la figura del director general de instrucción pública, uno de manera central para todo el país y en cada uno de los Estados que conformaban la unión colombiana. Además, que se establecieron los métodos de enseñanza, reglamentos en las escuelas, que incluía la parte de la disciplina, castigos, asistencia de los niños y premios, creación de escuelas normales en cada uno de los Estados e instauración de bibliotecas públicas. ${ }^{10}$ Esta reforma abarcó todos los niveles educativos -primaria,

\footnotetext{
${ }^{8}$ Archivo Histórico de Cartagena (en adelante AHC) Gaceta de Bolivar, (Cartagena) 30 de noviembre de 1870; BNC, “editorial” La Verdad, (Cartagena) 25 de diciembre de 1877: 3.

${ }^{9}$ Serrano 348.

${ }^{10}$ BNC, La Escuela Normal, (Bogotá) 7 de enero de 1871; La Escuela Normal, (Bogotá) 14 de enero de 1871.
} 
secundaria y nivel universitario- y le otorgó a la educación un sentido gratuito y obligatorio. Cuestión sui generis en el país y que sin duda marca un antes y un después en la historia educativa de Colombia, ya que toda la legislación anterior había definido la educación como gratuita pero no obligatoria. Tal principio de la obligatoriedad tenía como propósito esencial para los liberales radicales, como lo plantea Eugenia Roldan para el caso de México, cuando recalca que, el surgimiento de la obligatoriedad escolar moderna tuvo que ver menos con el propósito de dotar a los niños de las primeras capacidades intelectuales para la vida en las comunidades modernas, y más con un objetivo no explícito de darles una "introducción ceremonial", una iniciación que "convirtiera" simbólicamente a los niños no formados (salvajes) en individuos formados autorizados para participar en la economía, política y sociedad moderna. ${ }^{11}$ Se caracterizó, además, por plantear una concepción integral del problema educativo, desde la formación de maestros hasta la construcción de los edificios escolares. Con esta reforma:

por primera vez el país dio prioridad a la escuela de primeras letras. Por primera vez también se intentó establecer la escuela, gratuita y obligatoria y religiosamente neutral. Todo estaba allí previsto, desde la organización general administrativa, hasta los métodos de enseñanza, los sistemas disciplinarios, la forma y estilo de las construcciones escolares y los ideales morales. ${ }^{12}$

Esta reforma constituyó la edad de oro de la educación en Colombia, haciendo del sistema escolar una herramienta esencial para ir perfilando el anhelado Estadonación, así como instrumento de popularización de un ideal de ciudadano y de puesta en práctica de separar la influencia de la Iglesia católica en la enseñanza. ${ }^{13}$ En suma, podemos manifestar, que la educación fue uno de los principales tópicos que mayor atención ocupo por parte de los gobiernos radicales de la época, puesto que para estos líderes políticos se consolidaría como uno de los elementos fundamentales, no solo para divulgar el discurso a favor de la nación y avanzar en la tan ansiada homogenización de la sociedad republicana, sino también para alcanzar el desarrollo del país y un vehículo para que el pueblo accediera a sus libertades políticas. En otras palabras, la idea era formar hombres “civilizados", capaces de superar la ignorancia y alcanzar el anhelado progreso, tan necesarios y urgentes en estos tiempos de consolidación de la república. ${ }^{14}$

\footnotetext{
${ }^{11}$ Eugenia Roldán, "La escuela mexicana decimonónica como iniciación ceremonial a la ciudadanía: normas, catecismos y exámenes públicos”, Ciudadanos inesperados. Espacios de formación de la ciudadanía ayer y hoy, coords. Ariadna Acevedo y Paula López (México, El Colegio de México, Centro de Investigación y de estudios avanzados, 2012) 39.

12 Jaime Jaramillo Uribe, "El Proceso de la educación desde el Virreinato a la época contemporánea", Manual de Historia de Colombia, tomo III, 2da. (Bogotá: Procultura, 1982) 264-265.

${ }^{13}$ Silva Renán, "La educación en Colombia, 1880-1930”, Nueva Historia de Colombia, vol. 4 (Bogotá: Ed. Planeta, 1991): 62-63.

${ }^{14} \mathrm{Si}$ hacemos una lectura comparativa con otros países de Hispanoamérica, observamos que también existió ese interés por fomentar el ramo estatal de la educación pública. El caso de México es ilustrativo, pues se expidió una Ley Orgánica de Instrucción Pública el 2 de diciembre de 1867 y una reforma a esa misma ley el 15 de mayo de 1869. Tal como lo señala, la historiadora Josefina Vázquez, esta ley demostraba en qué medida la educación pública era una preocupación central de la República Restaurada, pues estableció la instrucción primaria gratuita para los pobres y obligatoria, excluyendo toda enseñanza religiosa del plan de estudios. Similar que en Colombia, los liberales de México creyeron en el poder de la educación,
} 
Contrario a ello, la carta magna de 1886 establece el proyecto político de la Regeneración y desde su primer epígrafe enuncia: “[...] en nombre de Dios fuente suprema de toda autoridad", por lo que la preeminencia del elemento religioso y cristiano será un factor primordial; de hecho, consideraba la religión católica, apostólica y romana la única religión oficial del país y promulga que sea respetada y protegida como elemento esencial del orden social; promueve la reconstitución de la forma de república unitaria y centralizada, dividida en departamentos y no en estados soberanos; la educación pública, organizada y dirigida por la religión católica, gratuita pero no obligatoria; establece, asimismo, que los sacerdotes puedan ser nombrados empleados para instrucción pública o de beneficencia; libertad de prensa, pero sujeta a las leyes estatales; restricciones en la libertad de poseer y comprar armas, es decir que solo el gobierno lo podrá hacer; la ciudadanía se adquirirá al ser mayor de 21 años y ejercer alguna profesión, arte u oficio, o al tener ocupación lícita u otro medio legítimo y conocido de subsistencia; si no se es ciudadano tampoco se pueden ejercer funciones electorales ni desempeñar empleos públicos, fortalecimiento del poder ejecutivo, entre otros aspectos.

Es decir, de una república liberal federal con una neutralidad religiosa en asuntos educativos y políticos, que intentó construir una colectividad de valores modernos se pasó a un régimen que se inclinaba por el rescate de esos valores tradicionales y donde la puesta en marcha de una política moderna pasaría, sin duda, por la tutelar importancia y el filtro del fuero eclesiástico. ${ }^{15}$ De un intento por deshacer el tejido social durante la época liberal, se volvió a pensar la sociedad con la intención de anular al individuo y mantener el orden de esa estructura social. Por lo tanto, a lo que asistimos en nuestro país en las tres últimas décadas del siglo XIX, es a un régimen estatal que como la Regeneración se caracterizó por un centralismo políticoadministrativo, autoritarismo y restricciones en libertades civiles, restitución del Estado confesional, imposición de una sociabilidad conservadora y también de tipo confesional; el ascenso de un personal político que tuvo en común haber rivalizado con el Liberalismo radical, pacto entre la Iglesia y el Estado con el Concordato, retorno de los jesuitas y un culto a la cultura española como símbolo de identidad nacional.

para transformar su país. Lo que nos permite reflexionar precisamente en que fue la educación casi que, en la gran mayoría de países de América Latina en la segunda mitad del siglo XIX, un elemento esencial para la transformación de la sociedad, erigir Estado-nación y formar ciudadanos. Josefina Vásquez, "la República Restaurada y la Educación. Un intento de victoria definitiva", La educación en la historia de México (México: El Colegio de México, 1995) 102.

${ }^{15}$ Para el historiador Edwin Cruz, "A diferencia del proyecto de nación del Radicalismo, que enfatizó la integración en la diferencia por medio del federalismo y la educación para formar ciudadanos libres e iguales, en el proyecto regenerador la integración vendría dada por el rescate de las tradiciones que, como se supuso, expresaban la "esencia" o ser nacional, y un Estado centralista y autoritario soportado en la Iglesia católica. El discurso de la Regeneración representó en forma hegemónica la "esencia” de la nación colombiana como católica, hispanohablante y mestiza. El concepto de nación en este proyecto ya no sería la nación liberal, legado de la Revolución Francesa, sino un concepto centrado en la comunidad de tradiciones y la autoridad como elementos cohesionadores. En ese sentido, es más cercano a los conceptos primordialitas de nación en los que esta se define por atributos como la lengua, en este caso el castellano, y criterios raciales, en este caso el mestizaje". Véase: Edwin Cruz Rodríguez, "La nación en Colombia del Radicalismo a la Regeneración (1863-1889): Una interpretación política”, Pensamiento Jurídico 28 (2010): 69-104. 
Tal como ocurrió durante la época liberal, es la instrucción pública un elemento esencial para los gobiernos de la Regeneración y un instrumento fundamental para el progreso del país, así como una preocupación constante de su proyecto político. Pero con la diferencia, que, durante todo este periodo, la instrucción pública primaria será gratuita, pero no obligatoria. Se preceptúa que la religión católica sea enseñada de manera obligatoria en las universidades, en los colegios, en las escuelas y en los demás centros de enseñanza, en tanto que los padres no se opongan abiertamente a ellos y se les confiere a los señores curas, la facultad de dar la enseñanza cristiana en los establecimientos públicos que lo exijan y que ellos lo determinen. ${ }^{16}$

Una de las primeras iniciativas de los políticos regeneradores, en su interés por la instrucción, fue precisamente reorganizarla con la ley "89 de 1888" expedida el 7 de noviembre del mismo año. Dicha ley consagraba al gobierno y en su primer rótulo lo anuncia, las funciones de reglamentar, dirigir e inspeccionar la instrucción pública, así primaria como secundaria que sea costeada por fondos de la nación, de los departamentos y de los distritos, o que se den en establecimientos que por su naturaleza tengan el carácter de público, ejercerán las facultades que le da la Constitución y las leyes sobre instrucción pública. Así mismo, se señala que la instrucción pública secundaria se dará en la Universidad Nacional y en los institutos públicos ejercidos en los departamentos para inspeccionar la enseñanza en los establecimientos públicos. El gobierno podrá crear juntas o comisiones de carácter permanente en las localidades respectivas. Este decreto, se puso a tono de manera estructural con los asuntos inherentes a la educación pública. En él se precisa el papel de las asambleas departamentales en el fomento a la instrucción, las funciones de los directores de escuelas y directoras, los requisitos para ser admitido en una Escuela Normal, los gastos de la nación con respecto a la instrucción, los sueldos de los directores y directoras de escuelas públicas, la autonomía que tiene el fuero eclesiástico para ejercer sus funciones que le otorgó la Constitución y el acuerdo entre el papa y el gobierno. ${ }^{17}$

Fomentar la enseñanza pública se convirtió en un aspecto central en las preocupaciones de este notablato durante todo su periodo gubernamental. En su imaginario concebían que: "la propagación de la instrucción pública es una de las necesidades de primer orden porque es menester que los ciudadanos todos estén en capacidad de seguir con interés el curso de los negocios públicos y porque como todos sabemos con la

\footnotetext{
${ }^{16}$ Esto de hecho es constitucional, pues en el artículo 41 de la Constitución de 1886, se establece que "[...] la educación pública será organizada y dirigida en concordancia con la religión católica. La instrucción primaria costeada con fondos públicos será gratuita pero no obligatoria". Véase: Constitución de la República de Colombia, edición oficial científicos de Antioquia, imprenta de vapor de Zalamea. 1886. El decreto que establece esto es el "544 de 1888" firmado por el presidente de la republica Rafael Núñez y el ministro de instrucción pública Julio Casas Rojas, acordémonos que también esto hizo parte, del contrato celebrado entre este gobierno y el vaticano. Véase: BNC, "Decreto 544 de 1888", Registro de Bolívar, (Cartagena) 23 de agosto de 1888: 3; Revista Escolar, (Cartagena) 31 de octubre de 1888: 12.

${ }^{17}$ Cabe mencionar que lo firman el presidente del senado J. A. Pardo, el presidente de la cámara de representante Manuel Ortiz, el secretario del senado Diego Guzmán, el secretario de la cámara de representante Salvador Franco, el ministro de instrucción pública Julio Casas Rojas y por supuesto el presidente de la república Carlos Holguín. BNC, "Decreto 89 de 1888", Revista Escolar, (Cartagena) 30 de enero de 1889: 60.
} 
instrucción desaparecen los principales inconvenientes que dificultan el progreso de la patria". ${ }^{18}$ En efecto, lo que presenciamos durante la Regeneración, si bien a una necesidad por instruir a la población; y hacer de la educación pública, un vehículo para que el pueblo accediera al espacio político, también es cierto, que tal enseñanza debía de hacerse en función de la doctrina católica, hecho que marca una diferencia radical con el liberalismo, que dicho sea de paso plantearon una neutralidad religiosa en ese sentido. Para los regeneradores:

[...] el catolicismo es el único poder capaz de restablecer fundamentalmente el orden perturbado de manera tan profunda en las sociedades políticas. Los espíritus poseídos de solida instrucción religiosa niegan todo exceso a los errores que con envoltura fillosófica o económica socavan la sociedad moderna, contra las cuales es impotente la fuerza material de los ejércitos y los desvelos de la ciencia laica. ${ }^{19}$

Estos políticos concibieron la educación, como uno de los escenarios donde no solo reproducían sus distintas formas de dominación, sino también el teatro, para la formación de los nuevos ciudadanos, moralmente aptos que necesita la república, pero en articulación con los dogmas católicos. Ahora bien, pese a sus diferencias con el liberalismo, fue la instrucción pública en ambos proyectos, un vehículo esencial en el proceso de formación del Estado-nación, homogeneizar la sociedad en torno a un mismo principio y lenguaje instruccionista, pero sobre todo formar esos ciudadanos que debían habitar en estos espacios republicanos. Pero hay otro elemento que me permiten inferir, que, a pesar de ser disímiles proyectos políticos, de concebir el Estado en Colombia entre 1870-1899; y múltiples maneras de hacer sociedad, con respecto a la puesta en marcha de sociabilidades institucionalizadas para el fomento a la instrucción pública, sostenemos que hubo otra continuidad en estos proyectos políticos, tan divergentes de concebir y pensar el Estado. Pero, además, estas sociabilidades creadas por esta dirigencia se constituyen en herramientas esenciales para la dinámica de la política moderna y el protagonismo del individuo en este escenario, pues a través de ella como ya lo veremos hay un interés por descorporativizar la sociedad. Así como el importante papel que cumplió en la legitimación de un mismo discurso educativo, la formación de ciudadanos y en la representación que desde esos espacios hacen del maestro de escuela como el paradigma de la ciudadanía. En las próximas líneas, se hará un análisis de las principales características de esas interacciones y los distintos caracteres construidas en el campo de la educación pública a través de las sociabilidades, tanto en el proyecto educativo liberal como regenerador en el Bolívar Grande.

\footnotetext{
${ }^{18}$ BNC, "Instrucción siempre", El Gladiador, (Cartagena) 30 de abril de 1889: 2.

${ }^{19} \mathrm{BNC}$, "Informe del rector del Colegio de Bolívar, Francisco Escobar al ministro de instrucción pública", Registro de Bolivar, (Cartagena) 14 de julio de 1892: 7.
} 


\section{Formar sociedades sí "queréis ver cumplidos vuestros deseos"20}

Un historiador autorizado nos había anunciado hace ya varios años en un libro pionero sobre el tema de las sociabilidades en Colombia entre 1820-1886, que con oleadas de prevención o de entusiasmo, la cultura política en el siglo XIX acudió al fenómeno asociativo como un mecanismo que contribuyó a definir lealtades y a identificar adhesiones. El hombre o la mujer solitarios estaban desahuciados para la vida pública y era entonces indispensable pertenecer a algo, reunirse en algún lugar. La tertulia en un café, la reunión en las galleras, en la casa de un artesano, en el taller de imprenta, en el templo católico, en la plaza central, la tenida de una logia y la sesión en un salón de la escuela primaria. La sociabilidad según tal historiador, se volvió gradualmente un mecanismo inherente al moldeamiento del espacio cotidiano de disputas políticas; se impuso la asociación como un instrumento de reconocimiento de derechos individuales, como el lugar donde el individuo podía opinar libremente y adquirir algunos conocimientos básicos de sus derechos y deberes en la categoría de ciudadano. ${ }^{21}$

Formar sociedades si "queréis ver cumplidos vuestros deseos"22 así como "el hombre no puede vivir sin el hombre. Desde que abre el ojo a la luz, hasta que cae en el sepulcro, tiene necesidad de ser ayudado". ${ }^{23}$ Era el llamado de dos medios impresos de la ciudad de Barranquilla al público lector y el clamor que desde sus páginas reproducían al seno de la sociedad bolivarense. En efecto, un elemento central, para seguir complejizando de mejor manera, los dispositivos hegemónicos llevados a cabo por el Liberalismo radical y la Regeneración, en sus apuestas por fomentar una educación pública de corte laica y luego cristiana con principios progresistas, es el fenómeno asociativo en la gran mayoría de corte formal e institucional. Hay un despliegue de estas civilidades a lo largo del Bolívar Grande, que responden al eco impulsado por la prensa, pero sobre todo al interés estatal por promoverlas y la propia voluntad de los individuos por asociarse. En razón de su importancia, iniciaremos el recorrido por cada una de ellas en el espacio geográfico objeto de estudio.

En un decreto creado el 13 de octubre de 1866 y materializado en febrero de 1870 avalado por el entonces presidente del Estado Soberano de Bolívar, M. Amador Fierro y su secretario general M. M. Casas. Pone en funcionamiento, -en el marco de la dirigencia liberal y en el afán por parte de estos políticos de popularizar la instrucción

\footnotetext{
${ }^{20}$ BNC, "Formar sociedades", La Voz, (Barranquilla) 27 de octubre de 1892: 2.

${ }^{21}$ Loaiza 20.

22 BNC, "Formar sociedades", La Voz, (Barranquilla) 27 de octubre de 1892: 2.

${ }^{23}$ BNC, "La Sociedad", El Comercio, (Barranquilla) 8 de agosto de 1892: 438. Otros diarios que impulsaban la creación de asociaciones en el Caribe colombiano, véase en: BNC, "sociedades de socorros mutuos", Diario Comercial, (Barranquilla) 26 de marzo de 1897: 2; BNC, "ASOCIACIÓN", Diario Comercial, (Barranquilla) 29 de febrero de 1896: 146; BNC, "SOCIEDAD COOPERATIVAS (conclusión)", Diario Comercial, (Barranquilla) 14 de agosto de 1897: 2; BNC, Revista Mercantil, (Barranquilla) 20 de marzo de 1890.
} 
pública, así como en la perspectiva de asociar a individuos en pro del fomento a la educación y por legitimar un mismo discurso instruccionista-, las juntas subalternas de instrucción pública. Ese mismo decreto establecía que tales juntas tendrían presencia:

[...] en las capitales de provincias $i$ en aquellos otros distritos en que exista ciertos números de ciudadanos que, por su idoneidad i patriotismo sean capaces de cooperar al fomento de la instrucción pública [...] El personal de cada junta subalterna será de cinco miembros principales, que tendrán sus correspondientes suplentes, elegibles unos i otros por la mayoría absoluta de los miembros presentes de la junta superior de instrucción pública. Estas juntas tendrán un presidente, un vicepresidente i un secretario. ${ }^{24}$

Tales principios asociativos nos ofrecen ciertas lecturas. La primera era la finalidad con la cual se creaban. Se buscaba impulsar con la ayuda de ciudadanos íntegros la consolidación de la instrucción pública. Así mismo, vislumbra el carácter no impositivo de los miembros que harán parte de tales juntas, todo lo contrario, se convocaba a los más honorables y colaboradores para que coadyuven a la buena marcha del campo educativo. Además, se refleja el carácter organizativo y el número de miembros que acompañaran las sesiones. Tales juntas tuvieron como deberes esenciales: visitar las escuelas públicas de las provincias y distritos del Estado, vigilar la conducta de los maestros tanto en el aula de clases como por fuera de ella, cuidar de que los sueldos de los empleados antes mencionados fueran cubiertos religiosamente, examinar a los alumnos de las escuelas públicas al fin de cada trimestre, presentar cada tres meses a la junta superior de instrucción pública, un informe sobre el estado de la instrucción en las provincias y distritos del Estado y levantar el espíritu público a favor de la instrucción pública, principalmente a los padres de familia, la conveniencia que resulta a la sociedad de que los ciudadanos sean instruidos, fomentar por todos los medios que estime a su alcance la instrucción pública y estudiar los resultados que produzca el método de enseñanza que se practica en las escuelas oficiales. ${ }^{25}$

Es clara la intención de crear, por ejemplo, juntas subalternas de educación para el fortalecimiento y la popularización de este ramo. Debían ocuparse estructuralmente del tema en cuestión, pues su labor iniciaba desde las mismas visitas a las escuelas de las provincias y distritos como la de estar muy alerta con la conducta de los maestros de escuelas, tanto dentro del espacio escolar como en su vida pública. Al mismo tiempo, tenían que velar por el pago de sueldos puntuales a los maestros y la nada desdeñable tarea de evaluar cada tres meses a los alumnos, para determinar cuánto avanzan o no en la enseñanza, la apropiación de los métodos de enseñanza modernos, en los niños y en los futuros ciudadanos que se forman en las escuelas. No menos importante, era penetrar en los padres de familia los múltiples beneficios que recibirán sus hijos con la ilustración, que ante la falta de cultura escolar preferían enviar muchos de ellos al

\footnotetext{
${ }^{24}$ AHC, "ACUERDOS de la Junta Superior de Instrucción Pública. Que organiza las Juntas Subalternas de instrucción pública”, Gaceta de Bolivar, (Cartagena) 6 de febrero de 1870: 50-51. Este tipo de juntas fueron avaladas por el presidente del Estado M. Amador Fierro y su secretario general M. M. Casas.

${ }^{25}$ AHC, “ACUERDOS de la Junta Superior de Instrucción Pública. Que organiza las Juntas Subalternas de instrucción pública”, Gaceta de Bolivar, (Cartagena) 6 de febrero de 1870: 50-51.
} 
acompañamiento en sus labores del campo. En definitiva, les correspondía convertirse en motores permanentes para el fomento y la consolidación de la instrucción pública. De su buena labor dependía buena parte de los frutos esperados por los liberales radicales en este campo y el convencimiento de alfabetizar el mayor número de personas para ampliar la ciudadanía a un buen porcentaje de la población tan carente de derechos políticos y civiles.

En las diversas sesiones llevadas a cabo en las escuelas de las mismas provincias y distritos del Bolívar Grande se puede corroborar que tales juntas respondían a los objetivos bajo las cuales fueron creadas. Era muy recurrente en sus reuniones presididas por sus distintos miembros y en el cual quien daba apertura a las deliberaciones era precisamente el presidente, mientras que el secretario tomaba los apuntes para enviarlos al director de instrucción pública del territorio, hacer un balance del estado físico de los espacios escolares, así como la cantidad y calidad de los textos y útiles de enseñanza, sobre la negativa de los padres de familia por enviar a sus hijos a las escuelas, debido en gran parte a la pobreza que los embargaba; se debatía mucho sobre el papel que estaban llamados a cumplir los alcaldes y concejos en el fomento a la instrucción pública. Así mismo, y esto es esencial, para coadyuvar al impulso de la educación y buscar las medidas más eficaces para resolver cualquier asunto inherente a este ramo. No eran las simples reuniones para mirar la radiografía de la dinámica educativa, era enlazar a los distintos grupos sociales para la búsqueda de soluciones y hacer de la educación pública el verdadero camino para la ilustración de todos los ciudadanos; y un instrumento imprescindible para el progreso de la sociedad. Estas juntas pronto se convirtieron en una herramienta esencial para el fomento y la popularización de la enseñanza pública. Reflejaban el apoyo incondicional que por la ilustración del pueblo materializaron los miembros que hacían parte de estas reuniones. Así lo manifiesta el presidente de la junta superior de instrucción pública Federico Núñez en una intervención que realiza en una sesión de la junta subalterna de la provincia de Magangué:

Comienza ya experimentarse los benéficos resultados que eran de esperarse del saludable impulso comunicado por la leí últimamente espedida, al más importante de los ramos que deben ocupar seriamente la atención de un gobierno ilustrado. La instrucción pública, merced a ese vigoroso impulso, va tomando un vuelo prodijioso, i dentro de poco no habrá persona, por limitada que sea su intelijencia, que no esté penetrada de su importancia, así como también de la necesidad i conveniencia de que el gobierno la proteja decididamente i la difunda por medio de escuelas gratuitas bien dotadas i mejor servidas, hasta en los más insignificantes distritos. La junta subalterna de la provincia de Magangué ha dado principio a sus tareas penetrada de un espíritu eminentemente patriótico, mui digno del carácter personal i de la ilustración de sus miembros. ${ }^{26}$

Con este discurso se hacía eco de la ilustración que invadía a los distintos grupos sociales. Existió en este ambiente de reuniones la visión de dejar atrás el oscurantismo

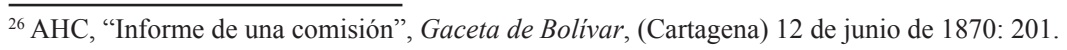


y la ignorancia, por iniciar el camino de instrucción y así poco a poco tener más cerca la idea de progreso y de civilización, tan anhelados en ese momento. Por supuesto que esto acompañado de los distintos impulsos que desde la dirigencia liberal se estaban promoviendo para recoger los frutos esperados. Tenían claro que la instrucción de las masas era un puente seguro para la fuerza productiva y así formar a los nuevos ciudadanos en algún arte u oficio como vehículo para su desenvolvimiento en la vida y en la nueva sociedad republicana.

No solo fue en función de la enseñanza masculina la puesta en marcha de sociabilidades para impulsar y popularizar desde este campo la educación pública. También se crearon para la instrucción femenina, hacia 1874, las comisiones de señoras y señoritas en cada provincia y distrito del Estado, por medio del decreto "13 de 1874 ", firmado por el entonces director de instrucción pública y por el secretario general de Bolívar. Estas comisiones fueron conformadas en su gran mayoría por mujeres que tenían ciertos prestigios en las poblaciones donde habitaban. Su función fue, vigilar el buen funcionamiento y desempeño de las escuelas de niñas, participar como juezas en las evaluaciones trimestrales y anuales, pero sobre todo levantar el espíritu público a favor de la instrucción pública, principalmente a los padres de familia, la conveniencia que resulta a la sociedad de que las mujeres sean instruidas. ${ }^{27}$ Con estas comisiones la dirigencia liberal intentó, además, que las mismas mujeres asumieran el papel de velar por su mismo progreso en el campo de la instrucción. En un informe anual del director de instrucción pública en el año de 1874 se corrobora esa visión colocando el ejemplo de las comisiones de Santo Tomas y Soledad, manifestaba lo siguiente:

[...] el procedimiento de aquellas cultas Señoras i Señoritas es consolador, como que manifiesta que, entre nosotros las mujeres empiezan a comprender su augusta misión; i hace esperar que no mui tarde se pondrán al frente de la educación popular, como lo ha verificado la Gran Republica del Norte. ¡Ojalá que las demás comisiones del Estado imiten la noble conducta de las de Santo Tomas i Soledad! ${ }^{28}$

Lo que podemos interpretar con este tipo de asociaciones tanto para hombres como para mujeres en el campo de la educación pública, es que existió una preocupación por parte de los políticos liberales por crear herramientas para popularizar este ramo. La idea fue proyectar en los individuos que hacían parte de estas deliberaciones un mismo discurso instruccionista y un mismo cuadro para hacer de la educación vehículo esencial en la formación de ciudadanos y del anhelado Estado-nación. Pero, además, se vislumbra el papel protagónico que empiezan a tener los individuos, si bien inmersos en la hegemonía estatal, en la política moderna. La libertad de asociarse nos conduce a mirar la apropiación que existió por parte de las personas de los distintos derechos políticos, civiles y sociales que en este contexto liberal poseen. Lo que permite reflexionar y aquí sigo los planteamientos de Pilar González para el caso de Argentina entre 1829-1862 que, la asociación es concebida como una forma

\footnotetext{
${ }^{27}$ AHC, "Comisiones de señoras y señoritas. Decreto 13 de 1874", Gaceta de Bolívar, (Cartagena) 15 de septiembre de 1874; (Cartagena) 31 de diciembre de 1874 y (Cartagena) 29 diciembre de 1874.

${ }^{28} \mathrm{AHC}$, "Informe anual de instrucción pública", Gaceta de Bolívar, (Cartagena) 15 de septiembre de 1874: 10.
} 
de pedagogía cívica, mediante la cual el ciudadano hace el aprendizaje de la cosa pública, constitutiva de la comunidad; la práctica asociativa, que por otra parte, supera el ámbito de esas elites, se inscribe en una red de relaciones, que rompe con el marco local de referencia e instaura, un nuevo espacio de relaciones, a partir del cual, la sociedad se piensa como agregado de individuos racionales; y el lazo social, como el producto de un contrato voluntario. ${ }^{29}$ Es decir, son en estos espacios donde se perfila y se inventa al individuo como sujeto principal de dispositivos modernos.

En este mismo escenario fue creada la Sociedad de Institutores. Sus miembros eran los directores y subdirectores de las escuelas de ambos sexos que pertenecieran al territorio bolivarense, miembros de los consejos de instrucción pública, "amigos de la educación que sean nombrados por la sociedad" y así mismo, los alumnos de la escuela que la misma sociedad contemple. Su presidente era el director de la Escuela Normal Nacional de Bolívar y debían reunirse todo el año en los días que determinara el poder ejecutivo y el presidente de la sociedad. Dicha sociabilidad tuvo como propósito: conservar vivo en los institutores públicos el sentimiento de vocación y continuar su instrucción por reuniones regulares, así como en lecciones aisladas, consultas, conversaciones, tesis escrita, estudios de ramos particulares de enseñanza, lecturas y los demás medios indicados por la reglamentación educativa; mantener constantemente en agitación el espíritu público para la difusión de las luces, promover contribuciones voluntarias con el mismo objeto; buscar los medios de llevar la instrucción a los caseríos distantes de las escuelas; apoyar y levantar a los jóvenes que por su pobreza se hallen imposibilitados para desarrollar sus talentos; estudiar y proponer al director de instrucción pública las medidas convenientes para el progreso de la instrucción popular; trabajar en la perfección de los métodos y textos de enseñanza; mantener correspondencia con las sociedades de la misma especie de otros Estados sobre objetos relacionados con el progreso de la instrucción; dirigir y auxiliar con sus trabajos a los directores de escuela que no hayan completado su educación o que no tengan la práctica suficiente en el arte de enseñar; sostener el honor de la profesión haciendo que los institutores públicos sean el modelo de los buenos ciudadanos y por último, no menos importante, apoyar eficazmente todos los esfuerzos del director de la instrucción pública para procurar la difusión de las luces en todas las clases sociales. ${ }^{30}$

Este tipo de sociabilidades institucionales nos permiten interpretar, por un lado, la sumatoria de esfuerzos que desarrolló el notablato político liberal por mantener siempre viva la aptitud de los futuros maestros en el papel que estaban llamados a cumplir con su profesión en el seno de la sociedad. Se buscaba el no aislamiento de la esencia de su formación y convertirlo en un sujeto central en la propagación de la educación pública. Pero también eran imprescindibles estos espacios como teatro para construir, sostener y proyectar a ese maestro como el modelo de ciudadano ideal. No bastaba con la enseñanza en la Escuela Normal, sino que a la par se hacía necesario

\footnotetext{
${ }^{29}$ Pilar González Bernaldo, Civilidad y Politica en los orígenes de la Nación Argentina. Las Sociabilidades en Buenos Aires, 1829-1862 (México, Fondo de Cultura Económica, 2001) 406.

${ }^{30}$ BNC, La Escuela Normal, (Bogotá) 14 de enero de 1871: 2.
} 
crear herramientas para fortalecer aún más esa representación. De ahí la importancia de concentrarlos en estos lugares sociales. Una interacción que, al mismo tiempo, buscaba el impulso y la consolidación de la educación pública a lo largo y ancho del Bolívar Grande, donde el pedagogo desempeñaba un papel clave en esos propósitos. Desde la promulgación del Decreto Orgánico de Instrucción Pública, creado por los liberales en 1870 que transformó este campo en todos los niveles educativos, se analiza no solo la inauguración en nuestro país por modernizar la enseñanza y popularizarla, disciplinar a los individuos y controlarlos con el uso del tiempo en los espacios escolares, utilizar las escuelas como los espacios donde se forman los ciudadanos, sino también y esto resulta esencial, para explicar la creación de la sociedad de institutores, cuya representación era hacer de la labor del maestro formado en la Escuela Normal, una profesión modelo de la sociedad. Esta ideología estaba presente en las páginas de ese tratado educativo. En este decreto se reafirmaba lo siguiente:

El director de la escuela por la importancia i santidad de las funciones que ejerce es el principal funcionario del distrito, i tiene el deber de arreglar su conducta de manera que en su vida pública i privada sirva de tipo a todos los ciudadanos. Debe estar sostenido i animado por un profundo sentimiento de importancia moral de sus funciones, i fundar su principal recompensa en la satisfacción de servir a los demás hombres i de contribuir al bien público [...] será pundonoroso, leal en sus relaciones, benévolo i afable en sus tratos, cumplido en sus maneras. [...] en ningún caso se dejará arrastrar a efectos de pasión, ni incurrirá en otra debilidad que pueda comprometer su carácter, el cual debe formar un conjunto de virtudes varoniles. [...] las faltas contra el pudor, la temperancia, la moderación, el aseo, así como todo abuso patente en su vida doméstica, de la autoridad del padre, marido, jefe de familia, serán castigadas en un maestro de escuela con la pérdida del empleo. Le está prohibido el roce con personas reputadas de mala conducta i la frecuentación de tabernas casas de juego, no ponerse ni en una ocasión en estado de embriaguez; no estar nunca en pendencias ni dar escándalos; no apartarse ni un punto en fin de las buenas costumbres, no fumar jamás en presencia de los alumnos [...] las autoridades dispensaran a los directores de escuela una consideración especial i una deferencia respetuosa, en atención al augusto ministerio que desempeñan. ${ }^{31}$

En efecto, la sociedad colombiana y la bolivarense asistieron durante el periodo liberal radical al fomento del ideal que asumía al maestro como el prototipo de ciudadano. Sí la escuela era concebida como el teatro central en la formación de los nuevos hombres que necesitaba la república, el maestro era por tanto el primer ciudadano de ese espacio republicano. Por eso los esfuerzos por parte de los liberales por que fuera el sujeto central en la administración pública, pero además el modelo de ciudadano, ya que le correspondía no solo ser espejo ante todos por sus virtudes, sino que su vida tanto pública como privada debía estar siempre en estrecha relación con principios morales y honorables. No solamente estaba en juego su buena notoriedad, ante todo tenía que velar por mantener su trabajo, porque una falta en contra de lo que no le era permitido

\footnotetext{
${ }^{31}$ BNC, La Escuela Normal, (Bogotá) 7 de enero de 1871; La Escuela Normal, (Bogotá) 5 de septiembre de 1874: 277; La Escuela Normal (Bogotá)18 de enero de 1873; La Escuela Normal (Bogotá) 7 de enero de 1871 .
} 
era justa causa para relevarlo de su cargo. En otras palabras, para esta dirigencia él era la personificación real y viva del verdadero ciudadano, idealizado si se quiere, pero lo que interpreto durante todo este periodo, es a la sistemática representación en hacer del pedagogo sujeto central en la popularización de la enseñanza y el paradigma en la ciudadanía. Por eso su interés no solo en esbozarlo a través del mencionado decreto, sino que se construyen escenarios de deliberaciones como la sociedad de institutores donde se debatía sobre el estado de la educación, pero sobre todo sobre el papel que cumplía el pedagogo en la escuela y la imagen que tenía que proyectar como modelo de ciudadano ante los alumnos y la sociedad en general, pues era para esta dirigencia el modelo de la ciudadanía de su idealizada república.

Ahora bien, los regeneradores no se quedaron atrás en sus intenciones por impulsar y popularizar la educación pública mediante la creación de sociabilidades institucionales. Ni mucho menos proyectar al individuo como el sujeto central en la vida política, así como al maestro como modelo de ciudadano. Por supuesto que a partir de 1886 y contrario a sus antecesores de la mano con la Iglesia católica y un retorno precisamente a la restauración de los valores tradicionales. Aunque esto no signifique que su proyecto político y educativo no vaya de la mano con aspiraciones modernas, pues como lo bien lo plantea, Sol Serrano para Chile decimonónico, es posible observar "la secularización desde la religión como cambio y no como ruina. Pues la Iglesia se inserta a la esfera pública moderna y a la sociedad civil"32 en la búsqueda incesante por no quedarse relegada en los laberintos "acostumbrados" de los grupos sociales. Lo que significa, que también sitúan su plataforma política, en pretender hacer de Colombia y el Bolívar Grande, escenarios desde donde seguir pensando y repensando la nación y por ende a la sociedad desde el plano educativo. Por ello crearon la Junta de Institutores que estuvo conformada por el inspector general de instrucción pública, maestras y maestros que se reunían una vez por año, o lo que se requería en cada provincia del territorio. Dichas juntas tuvieron la función de: estudiar las medidas convenientes para el progreso de la instrucción popular, trabajar en el perfeccionamiento de los textos y métodos de enseñanza, sostener el honor de la profesión para hacer que los institutores públicos sean el modelo de los buenos ciudadanos; $y$, por último, están revestidos para separar a cualquier maestro, director de escuela y subdirector de la misma, que por su conducta se haga indigno de su alto magisterio. A nivel nacional se creó la Junta Central de Institutores, conformada por el subsecretario de instrucción pública, inspector general de instrucción pública de Cundinamarca y el director de la Escuela Normal de Institutores de dicho departamento. Tenía como funciones esenciales: cuidar de que las sociedades de las provincias se reúnan en las épocas determinadas, recibir de los inspectores generales las disposiciones y acuerdos que ahí se pacten y presentar al ministerio de instrucción pública las reformas que se deben introducir en este campo. ${ }^{33}$

\footnotetext{
${ }^{32}$ Sol Serrano, ¿Qué hacer con Dios en la Republica? Politica y secularización en Chile (1845-1885) (Chile, Fondo de Cultura Económica de Chile, 2008) 22.

${ }^{33}$ BNC, Revista Escolar, (Cartagena) 15 de marzo de 1890; Revista Escolar, (Cartagena) 15 de diciembre de 1888 .
} 
Las reuniones se realizaban en los locales de las escuelas, en provincias y distritos, en Cartagena, por ejemplo, se reunían en la sede principal de la Escuela Normal Nacional de Bolívar (Hoy Universidad de Cartagena, sede San Agustín) previa fecha asignada por el presidente de la junta. En una de las sesiones realizadas, en la provincia de Mompox, el presidente de la junta José Gutiérrez de Piñeres, en plena sesión de instalación, además de saludar a los asistentes y de darle la bienvenida, manifestaba lo que según él, es lo más relevante del régimen regenerador, con respecto a la instrucción pública. Para Gutiérrez de Piñeres:

[...] el bien más grande que la Regeneración ha hecho a la Republica, ha sido indudablemente volver á fundar sobre la enseñanza pública sobre la sólida base de la moral cristiana, esmerarse en que, al mismo tiempo y aun antes que se llene la mente de los niños con verdades científicas se enriquezca su corazón con virtudes y se adorne su parte externa con buenas maneras. ${ }^{34}$

Estos discursos, intentan construir un mismo lenguaje instruccionista, ${ }^{35}$ entre todos los que integran las juntas. No en vano siempre se está difundiendo, sobre la importancia de la educación moral, para el progreso social y de las distintas formas que debe inculcarse en los niños y niñas, pero siempre con fines cristianos. Por eso legitiman que bajo este régimen la enseñanza en las escuelas y universidades exista una estrecha relación con los dogmas católicos. Tanto es así, que el presidente de la junta de institutores, de la provincia de Cartagena, Juan Gastelbondo en 1889, les insistiera a sus colegas, sobre la gran necesidad que existía en nuestro país, sobre la educación. En una reunión de la mencionada asociación les recalcaba:

La gran necesidad hoy en Colombia, en lo que se refiere a instrucción pública, consiste en dar buenas costumbres y urbanas maneras a los niños, de preferencia a la educación intelectual, pues, la verdadera civilización, la constituye el respeto y la tolerancia, en armonía con la dignidad del individuo y la práctica de la justicia; ó en otros términos el cumplimiento de todos los deberes en el orden religioso y social, suficientes por si solos para el desarrollo de la riqueza, la armonía en los intereses y el progreso de mejora en los pueblos. ${ }^{36}$

\footnotetext{
${ }^{34}$ Estaban presentes en esa reunión los maestros de las escuelas de Turbaco, Antonio Carrasquilla, de Calamar Lorenzo Fernández, del Carmen Miguel Garcia, San Estanislao Fernando Padilla, Escuela Segunda de Cartagena, José Gory, Villanueva, Jesús Silva, Turbana, Juan González, Escuela Tercera, y Adolfo Visbal. B NC, "Discurso de José Gutiérrez de Piñeres, presidente de la junta de institutores de Mompox”. Revista Escolar, (Cartagena) 31 de marzo de 1889: 94-95.

${ }^{35}$ Aquí retomo los planteamientos de Marialba Pastor, que si bien se ocupa de otra época y otro espacio, si podemos observar la similitud en términos de construir un mismo discurso ideológico y con objetivos específicos. Cabe mencionar que esta historiadora reflexiona sobre los cuerpos sociales -órdenes religiosas, cofradías, colegios, gremios, familia, patriarcado- que, siguiendo "el modelo medieval", establecieron los hispanos en los siglos XVI y XVII en el territorio conocido como Nueva España. Plantea como estas corporaciones "[...] construyeron un lenguaje impositivo, que ese mismo lenguaje puso en común una misma ideología, una misma religiosidad, una sola visión del mundo. Su sistema de símbolos, sus expresiones y sus prácticas religiosas se correspondieron con la concepción sagrada del mundo que desplegó el catolicismo y con el interés del imperio por conservarse eternamente, para remitir a la comunidad al mito fundacional cristiano, al principio controlador del caos y a sus potencias, autoridades y personajes creadores y renovadores; al futuro prometedor y a sus inigualables santos". Véase: Miralba Pastor, Cuerpos sociales, cuerpos sacrificiales (México, Universidad Nacional Autónoma de México, Fondo de Cultura Económica México, 2004) 303.
}

${ }^{36}$ BNC, Revista Escolar, (Cartagena) 31 de marzo de 1889: 95. 
Este tipo de disertaciones vislumbra el papel que cumple la educación como vehículo para que el individuo no solo sea un ciudadano íntegro de valores, sino también formarlo en conjunto para la adquisición de tales prácticas. Constituyen estas sociabilidades institucionales difusoras de un tipo de educación si bien inmersas en el rescate de valores cristianos, al mismo tiempo propenden, para que esta sea un elemento esencial para el progreso y civilización para todos y además una de las herramientas para que el pueblo acceda y se apropie de sus libertades políticas. Reafirman estas reuniones un proyecto político, un discurso hegemónico que proyecta un tipo de individuo y de sociedad moderna en contravía de los postulados tradicionales. Pero también construyen, al igual que los liberales radicales, la imagen del maestro, como el intermediario entre el Estado y los ciudadanos comunes y corrientes, para que difunda las bondades de este sistema educativo, propague los métodos de enseñanza y sea el modelo a seguir en este proceso de hacer y pensar en sociedad. Por eso una regla básica que siempre le exigieron al maestro los políticos conservadores y que el pedagogo no podía perder de vista en su vida profesional y personal era precisamente:

\begin{abstract}
Ser modelo de virtud, de decoro y buenos modales y procurar de un modo persistente que sus alumnos adquieran hábitos en ese mismo sentido; tener siempre presente que las cualidades del agente determinan el carácter y los resultados de la obra, que el maestro de escuela como el sacerdote y el hombre de estado ha de obrar sobre el espíritu y la conducta de sus subordinados; que a la larga nada influye tanto sobre la conducta como la conducta misma; que como la enseñanza el agente o gobernante se halla en más inmediato contacto con los gobernados, que en cualquiera otra profesión o situación social. El influjo de su conducta tiene que ser más eficaz; y que el maestro no solo enseña por medio de lo que dice, sino por medio de lo que hace, por medio de lo que es. ${ }^{37}$
\end{abstract}

Para el notablato liberal y los de la Regeneración, como brevemente ya lo vimos, tal perfil no encajaba en otra persona sino en el pedagogo. Se reitera la similitud que debe de tener en términos de buena conducta pública y privada tanto con el sacerdote como con el jefe de Estado. Su imagen incluso debía ser mucho más decorosa que cualquier otro funcionario de la administración pública. Porque de ahí dependía el respeto de todos los grupos sociales hacia su persona y la buena recepción de la enseñanza en los niños y en la que sin duda alguna "depende la victoria de la civilización sobre la barbarie". ${ }^{38}$ De ahí la preocupación por fortalecer aún más esa imagen del maestro. No en vano estas reuniones básicamente eran precedidas por los mismos pedagogos y funcionarios de la administración pública, así como personas amantes de la instrucción. Lo que refleja que fueron estos espacios verdaderos teatros en la puesta en marcha de la legitimación de los postulados ideológicos regeneradores, pero también incluir en esos propósitos a los individuos que se requerían en la república y adentrarlos en las dinámicas de la política moderna.

\footnotetext{
${ }^{37}$ BNC, Registro de Bolivar, (Cartagena) 31 de agosto de 1886; Registro de Bolivar (Cartagena) 24 de agosto de 1886. Además, véase: BNC, Registro de Bolivar, (Cartagena) 24 de noviembre de 1898.

${ }^{38} \mathrm{BNC}$, Registro de Bolívar, (Cartagena) 26 de agosto de 1886.
} 
Aunado a lo anterior también pusieron en marcha otra sociabilidad, llamada Junta Central. Estaba conformada por el prefecto de la provincia, por el fiscal del juzgado del circuito y de tres miembros más nombrados por el gobernador del departamento. Le correspondía: vigilar la marcha de los establecimientos públicos de instrucción secundaria, tomar medidas para allanar cualquier dificultad en la instrucción pública, velar para que los recursos invertidos en las escuelas sean bien aprovechados, vigilar que los sueldos de los empleados públicos en este campo sean cancelados oportunamente, fijar las materias que deben impartirse, hacer cumplir la enseñanza cristiana en las escuelas públicas y otras funciones que el mismo gobierno dispondrá en su momento. ${ }^{39}$ Tuvieron sus sesiones principalmente en las escuelas de las principales provincias, distritos y municipios del territorio. Al analizar las fuentes de la época, podemos dilucidar que se reunían trimestralmente; y por lo general se hacía referencia a falta de textos de enseñanza en las escuelas, retraso en el pago de sueldos a maestros y maestras, indiferencia de los padres de familia con la instrucción de sus hijos, la buena disposición de los maestros en la enseñanza religiosa y los buenos resultados de los niños con la puesta en marcha de los nuevos métodos pedagógicos. ${ }^{40}$

Estas asociaciones creadas tanto durante el Liberalismo radical como en la Regeneración entre 1870-1899, se constituyen en diversos impulsos a la instrucción pública en esta parte del Caribe colombiano, que si bien serán inspirados para legitimar la política educativa de estos grupos y sus dispositivos ideológicos, que son piezas claves no solo para integrar a los individuos y a los grupos sociales en la formación del Estado-nación y la alineación de ciudadanos, sino también hacer de la instrucción pública una herramienta esencial para construir diversas formas complejas de hacer sociedad y un elemento de popularización; así como de progreso para todos y todas. No menos importante, es la imagen que intentan construir del maestro de escuela como el paradigma de la ciudadanía, pues como hemos visto en varias de estas deliberaciones estuvo muy presente difundir este tipo de representaciones con respecto al pedagogo. En ultimas, estos "lugares sociales" marcan un antes y un después en la manera de concebir al individuo y de descorporativizarlo. Pero sobre todo de perfilar un principio educativo que respondiera a sus necesidades republicanas.

\section{Conclusiones}

En una editorial de un periódico de corte liberal en 1898 se reproducía en sus páginas un cuestionamiento profundo sobre la puesta en marcha de la Constitución de 1886, así como de las limitaciones impuestas a las libertades individuales, prácticas de fraudes en las elecciones y las distintas prohibiciones a la prensa que han llevado a cabo los políticos conservadores. También, señala una variable que resulta esencial para

\footnotetext{
${ }^{39}$ Al igual que la anterior, se logró formalizar en diversas provincias y distritos del Bolívar Grande. Como por ejemplo en Margarita, Mompox, Lorica, Barranquilla, Usiacuri, Tolú, Ovejas, Morroa, Sampues, Corozal, Magangué, Sincé, Sincelejo, San Fernando, Morroa, Cartagena, San Estanislao, Carmen de Bolívar, Calamar, Turbana, Turbaco, Arjona, Villanueva, Cartagena, Barranquilla, Soledad, Sabanalarga, Sabanagrande, Sincé, Chinú, Ayapel, Purísima, Santo Tomas, Suan, Turbaco, Arjona, San Estanislao, Sabanalarga, Santo Tomas, Baranoa, Soledad, etc. BNC, Revista Escolar, (Cartagena) 15 de junio de 1890. ${ }^{40}$ BNC, Revista Escolar, (Cartagena) 15 de junio de 1890: 4.
} 
establecer continuidades con respecto al fomento de la educación pública, entre los liberales radicales y los de la Regeneración. Para esta prensa podrían existir diferencias entre ambos proyectos políticos, pero: "la propaganda educacionista verdadera piedra angular del liberalismo, ha sido no solamente continuada con vigor y abnegación merecedores del más alto encomio, sino fecunda y brillantemente impulsada en los últimos años, con la introducción en los cursos de los métodos científicos que dan a la educación la base inconmovible de los estudios positivos". ${ }^{41}$ En efecto, es el impulso y fomento a la educación pública y en ella el ejercicio de sociabilidades de tipo institucional, una prolongación entre los liberales y regeneradores en el Bolívar Grande. Si bien estas interacciones obedecen a programas políticos disimiles en concebir el Estado en Colombia en las tres últimas décadas del siglo XIX y principios del XX, cuando uno observa los distintos objetivos por las cuales fueron creadas, los debates que en ella se reproducían y todos los principios inherentes al ramo educativo que en esos escenarios tomaban fuerza, es evidente que cumplen en los variados proyectos políticos, igual proyección social, de legitimar el discurso hegemónico enarbolados por estos dirigentes.

El fenómeno asociativo en este contexto significó un puente para hacer de la labor del maestro una profesión modelo de la sociedad. Para esta dirigencia era el pedagogo la encarnación del ciudadano del futuro y el sujeto central como intermediario entre el Estado y los grupos sociales para legitimar sus distintos proyectos públicos. En otras palabras, son los maestros como intelectuales orgánicos, las "células vivas de la sociedad civil y de la sociedad política", ${ }^{2}$ que cumplieron unas tareas muy específicas en la puesta en marcha de los proyectos educativos impulsados por liberales y regeneradores en las tres últimas décadas del Bolívar Grande decimonónico. Es decir, formar maestros en la Escuela Normal no fue algo sigiloso ni mucho menos aislado durante este escenario. De su vinculación a esos proyectos estatales y el papel que desempeñó tal maestro permite observar la intención de construir intermediarios civiles para acercar mucho más el país teórico al país real ${ }^{43}$ que había que edificar. Fueron ellos los llamados a materializar en la tribuna pública una misma sintonía con los preceptos ideológicos enarbolados por liberales y conservadores. Solo así se podría pasar de las altas redes del poder al encuentro y desencuentro con los sectores populares, porque les gustara o no era ahí donde su fuerza hegemónica debía descansar y propagarse. ${ }^{44}$

\footnotetext{
${ }^{41}$ BNC "Pesimismo político", El Liberal, (Cartagena) 24 de septiembre de 1898.

${ }^{42}$ Antonio Gramsci, "La formación intelectual”, Cuadernos de la cárcel 2, los intelectuales y la formación de la cultura (México, Juan Pablos Ed, 1975) 11-28; Luciano Gruppi, "El concepto de hegemonía en Gramsci" (México: Ed. de Cultura Popular, 1978) 109-111. Un estudio histórico de los intelectuales es: Jacques Le Goff, Los Intelectuales en la Edad Media (Barcelona: Gedisa, 1986) 170.

${ }^{43}$ Idea rescatada del estudio que para el caso de México realiza: Marcelo Carmagnani y Alicia Hernández, "La ciudadanía orgánica mexicana, 1850-1910”, Ciudadanía política y formación de las naciones. Perspectivas históricas de América Latina, coord. Hilda Sábato (México: El Colegio de México/Fideicomiso Historia de las Américas/FCE, 1999) 371-404.

${ }^{44}$ Un estudio que da cuenta cómo el pueblo irrumpe en el espacio público colombiano decimonónico y se vuelve un agente histórico, incómodo, pero necesario (idea que rescato), disponible para volátiles alianzas, capacitado para expandirse en diversas formas asociativas y decidido a forjarse un lugar en la vida republicana, es: Gilberto Loaiza Cano, "Del débil utopismo de las elites a la formación de una cultura
} 
Por eso esta representación la acompañaron de decretos afines que a la par de estas interacciones, se convirtieron en impulsos en la formación del maestro como el paradigma de la ciudadanía. No en vano desde los mismos reglamentos de las juntas creadas y los debates que en esos espacios se llevaban a cabo, un punto central en la agenda, era precisamente valorar el papel del pedagogo en las escuelas; en su vida pública y aun en la privada. Se exhortaba a todos los miembros de las mismas, a estar vigilantes en las actuaciones que debía cumplir este nuevo sujeto. Porque no solo simbolizaba el primer ciudadano de la república, sino que en gran parte en él estaban guardadas las esperanzas para el porvenir del territorio y de la sociedad bolivarense. En definitiva, fueron estas sociabilidades el teatro para descorporativizar a la sociedad y otorgarle protagonismo al individuo y transitar poco a poco hacia espacios homogéneos y modernos tanto en lo político, social, económico y cultural. Así mismo, como una herramienta que unida a la educación se convirtieron en vehículo esencial para hacer Estado y edificar sociedad en Colombia y en el Bolívar Grande.

\section{Bibliografía}

\section{Fuentes primarias}

\section{Fuentes de archivo}

Archivo Histórico de Cartagena, fondo educación.

Biblioteca Nacional de Colombia-Fondo Daniel Samper.

Constitución de la república de Colombia, edición oficial científicos de Antioquia, imprenta de vapor de Zalamea. 1886.

\section{Prensa}

Diario Comercial (Barranquilla) 1897-1896.

El Comercio (Barranquilla) 1892.

El Gladiador (Cartagena) 1889.

El Liberal (Cartagena) 1898.

Gaceta de Bolivar (Cartagena) 1870-1874.

La Escuela Normal (Bogotá) 1871-1873-1874

La Verdad (Cartagena) 1877.

política popular en Colombia", Mundos posibles. El primer socialismo en Europa y América Latina, coords. Carlos Illades y Andrey Schelchkov (México: El Colegio de México/UAM-Cuajimalpa, 2014) 189-230. 
La Voz (Barranquilla) 1892.

Registro de Bolívar (Cartagena) 1886-1888-1892-1898

Revista Escolar (Cartagena) 1888-1889-1890.

Revista Mercantil (Barranquilla) 1890.

\section{Fuentes secundarias}

\section{Libros}

Amaro Peñaflores, René y Rivas Hernández, Judith. De los procesos de consolidación y ruptura de las mutualistas a los primeros sindicatos en Zacatecas, 1870-1926. Zacatecas: Zezen Baltza Editores, Universidad Autónoma de Zacatecas, 2015.

Arango Jaramillo, Mario. Masonería y Partido Liberal Otra cara en la historia de Colombia. Medellín: Corselva Editorial, 2006.

Arango de Restrepo, Gloria. Sociabilidades católicas, entre la tradición y la modernidad. Antioquia, 1870-1930. Medellín: Universidad Nacional de Colombia, Sede Medellín-La Carreta Editores, 2004.

Bruno, Paula. Sociabilidades y vida cultural, Buenos Aires, 1860-1930. Quilmes: Universidad Nacional de Quilmes, 2014.

Bazant, Milada. Historia de la educación durante el Porfiriato. México: El Colegio de México, 1993.

Carnicelli, Américo. Historia de la masonería colombiana, 1833-1940. Bogotá: Artes gráficas, 1975.

González Bernaldo, Pilar. Civilidad y Política en los orígenes de la Nación Argentina. Las Sociabilidades en Buenos Aires, 1829-1862. México: Fondo de Cultura Económica, 2001.

Gruppi, Luciano. El concepto de hegemonía en Gramsci. México: Ed. de Cultura Popular, 1978.

Loaiza Cano, Gilberto. Sociabilidad, religión y política en la definición de la nación (Colombia, 1820-1886). Bogotá: Universidad Externado de Colombia, 2011.

Le Goff, Jacques. Los Intelectuales en la Edad Media. Barcelona: Gedisa, 1986.

Serrano, Sol. ¿Qué hacer con Dios en la Republica? Política y secularización en Chile (1845-1885). Chile: Fondo de Cultura Económica de Chile, 2008. 
Silva, Renán. “La educación en Colombia, 1880-1930". Nueva Historia de Colombia, vol. 4. Bogotá: Ed. Planeta, (1991).

Pastor, Miralba. Cuerpos sociales, cuerpos sacrificiales. México: Universidad Nacional Autónoma de México, Fondo de Cultura Económica México, 2004.

Pérez Toledo, Sonia. Trabajadores, espacio urbano y sociabilidad en la Ciudad de México, 1790-1867. México: Miguel Ángel Porrúa, Universidad Autónoma Metropolitana, 2011.

\section{Capítulos de libros}

Agulhon, Maurice. "Clase obrera y sociabilidad antes de 1848”. Historia Vagabunda. México: Instituto Mora, 1994.

Agulhon, Maurice. "Los chambrée en la baja Provenza: historia y etnología”. Historia Vagabunda, México: Instituto Mora, 1994.

Bazant, Milada. "La disyuntiva entre la escuela y la cosecha: entre las multas y los arrestos". El Estado de México de 1874 a 1910. Coords. Pilar Gonzalbo. México: El Colegio de México, 1990.

Carmagnani, Marcelo y Hernández, Alicia. "La ciudadanía orgánica mexicana, 18501910". Ciudadanía politica y formación de las naciones. Perspectivas históricas de América Latina. Coord. Hilda Sábato. México: El Colegio de México/Fideicomiso Historia de las Américas/FCE, 1999.

Caldo, Paula y Fernández, Sandra. "Sobre el sentido de lo social: asociacionismo y sociabilidad. Un breve balance". Ciudad oblicua. Aproximaciones a temas e intérpretes de las entreguerras rosarina. Comps. Fernández Sandra y Óscar Videla. Rosario: La Quinta Pata \& Camino Ediciones, 2018.

González Bernaldo de Quirós, Pilar. "Pedagogía societaria y aprendizaje de la nación en el Río de la Plata". Inventando la nación: Iberoamérica siglo XIX. Coords. Antonio Annino y François-Xavier Guerra. México: Fondo de Cultura Económica, 2003.

González Bernaldo de Quirós, Pilar. "Sociabilidad y regímenes de lo social en sociedades post-imperiales: Una aproximación histórica a partir del caso argentino durante el largo siglo XIX”. Sociabilidades en la historia. Coords. Santiago Castillo y Montserrat Duch. Madrid: La Catarata- Asociación de Historia Social, 2015.

Gramsci, Antonio. "La formación intelectual". Cuadernos de la cárcel 2, los intelectuales y la formación de la cultura. México: Juan Pablos Ed., 1975.

Guerra, François. "Una modernidad alternativa". Modernidad e independencias, ensayos sobre las revoluciones hispánicas. Coord. François Guerra. México: Fondo de Cultura Económica, 1993. 
Jaramillo Uribe, Jaime. "El Proceso de la educación desde el Virreinato a la época contemporánea". Manual de Historia de Colombia, tomo III, 2da (Bogotá: Procultura 1982).

Loaiza Cano, Gilberto. "Del débil utopismo de las elites a la formación de una cultura política popular en Colombia”. Mundos posibles. El primer socialismo en Europa y América Latina. Coords. Carlos Illades y Andrey Schelchkov. México: El Colegio de México/UAM-Cuajimalpa, 2014.

Mercedes, Betria. "Para una nueva lectura sobre la Generación del 37: mazzinismo y sociabilidades compartidas en la construcción de la identidad nacional argentina". Construcciones identitarias en el Río de la Plata, siglos XVIII-XIX. Coords. Arrigo Amadori y Mariano di Páscuale. Rosario: Prohistoria, 2013.

Ortiz Meza, Luis. "Los radicales y la guerra civil de 1876-1877”. El radicalismo colombiano del siglo XIX. Ed. Rubén Sierra Mejía. Bogotá: Universidad Nacional de Colombia, 2006.

Roldán, Eugenia. "La escuela mexicana decimonónica como iniciación ceremonial a la ciudadanía: normas, catecismos y exámenes públicos". Ciudadanos inesperados. Espacios de formación de la ciudadanía ayer y hoy. Coords. Ariadna Acevedo y Paula López. México: El Colegio de México, Centro de Investigación y de estudios avanzados, 2012.

Serrano, Sol. "La ciudadanía examinada: el control estatal de la educación en Chile, 1810-1870". Inventando la Nación. Ibero América Siglo XIX. Coord. Antonio Annino y François Guerra. México: 1ra Edición, Fondo de Cultura Económica, 2003.

Serrano, Sol. "La escuela chilena y la definición de lo público". Los espacios públicos en Iberoamérica, ambigüedades y problemas, Siglos XVIII y XIX. Coords. François Xavier Guerra y Annick Lémpèriere. México: Centro Francés de estudios mexicanos y centroamericanos, Fondo de Cultura Económica de México, 1998.

Thompson, E. P. “Tiempo, disciplina de trabajo y capitalismo industrial”. Costumbres en Común. Barcelona: Ed. Crítica, 2000.

Vásquez, Josefina. "la República Restaurada y la Educación. Un intento de victoria definitiva". La educación en la historia de México. México: El Colegio de México, 1995.

Wolf, Eric. "Relaciones de parentesco, de amistad y de patronazgo en las sociedades complejas". Teoría Social e Historia. Comp. Joan Vendrell Ferre. Madrid: Alianza Editorial, 1990. 


\section{Artículos de revista}

Alarcón Meneses, Luis. "Sociabilidad y relaciones de poder en el Caribe Colombiano durante el régimen federal". Revista Historia Caribe.2 (1996): 35-42.

Arango de Restrepo, Gloria. "Las cofradías, las asociaciones católicas y sus formas/ de/sociabilidad, Antioquia, siglo XIX”. Revista de Extensión Cultural 34-35 (1995): 94-104.

Cruz Rodríguez, Edwin. "La nación en Colombia del Radicalismo a la Regeneración (1863-1889): Una interpretación política”. Pensamiento Jurídico 28 (2010): 69-104.

Granja, Josefina. "Contar y clasificar a la infancia. Las categorías de la escolarización en las escuelas primarias de la Ciudad de México 1870-1930”. Revista Mexicana de Investigación Histórica 1.40 (2009): 217-254.

Hernández, Rubio y otros. "Movimiento asociativo en Santiago de Cuba: un acercamiento a sus orígenes y evolución durante el siglo XIX". Revista Historia Caribe 11.26 (2016): 51-75.

Lionetti, Lucía. "La función republicana de la escuela pública. La formación del ciudadano en Argentina a fines del siglo XIX". Revista Mexicana de Investigación Educativa 10 (2005): 1225-1255.

Loaiza, Gilberto. "Hombres de sociedades (Masonería y sociabilidad políticointelectual en Colombia e Hispanoamérica durante la segunda mitad del siglo XIX)". Revista Historia y Espacio (2001): 93-131.

Loaiza, Gilberto. "La masonería y las facciones del liberalismo colombiano durante el siglo XIX. El caso de la masonería de la Costa Atlántica”. Revista Historia y Sociedad 13 (2007): 65-89.

Loaiza, Gilberto. "Temporalidad, Sociabilidad y Democracia. Colombia y su Siglo XIX”. Revista Historia Caribe 11.26 (2016): 177-210.

Molina, Eugenia. "Sociabilidad y redes político-intelectuales: Algunos casos entre 1800 y 1852". Cuadernos del CILHA 12.14 Argentina, Universidad Nacional de Cuyo (2011): 19-54.

Solano, Sergio Paolo y otros. "Ordenamiento territorial y conflictos jurisdiccionales en el Bolívar Grande (Colombia), 1800-1886”. Historia Caribe.13 (2008): 65-121.

\section{Tesis, ponencias, documentos y otros Inéditos}

Álvarez Olivares, Juliana. "Hacerse artesano: identidad, diversidad y sociedad: Medellín,1854-1880". Tesis de Maestría en Historia, Medellín, Universidad Nacional de Colombia-Sede Medellín, 2008. 
Álzate García, Andrés. “Asociaciones, prensa y elecciones. Sociabilidades modernas y participación política en el régimen radical colombiano 1863-1876". Tesis de Maestría en Historia, Medellín, Universidad Nacional de Colombia, 2010.

Flórez Bolívar, Roicer. "El uso privado de la autoridad pública en el Estado Soberano de Bolívar, 1863-1878”. Tesis de Maestría en Historia, Cartagena, Universidad Pedagógica y Tecnológica de Colombia en convenio con la Universidad de Cartagena, 2007.

\section{Publicaciones en Internet}

https://www.academia.edu/15111086/Sociabilidad_asociacionismo_y_civilidad en_la_primera_mitad_del_siglo_XIX_neogranadino._Una_aproximaci\% $\%$ C3\%B3n_ conceptual (2014)

http://nuevomundo.revues.org/index24082.html (2008) 